\title{
Original
}

\section{Effect of the Surface Charge of Stainless Steel on Adsorption Behavior of Pectin}

\author{
ATSUHIKO TAKEHARA AND SATOSHI FUKUZAKI* \\ Industrial Technology Center of Okayama Prefecture, 5301 Haga, Okayama 701-1296, Japan
}

Received 23 March 2001/Accepted 21 July 2001

\begin{abstract}
The effect of the surface charge of stainless steel particles on the adsorption behavior of pectin was studied over the $\mathrm{pH}$ range of 2.5 to 5.0. Stainless steel particles having different surface charge properties were prepared by chemical passivation in nitric acid, ozone oxidation, and heat treatment. The degree of the ionization of pectin increased with increasing $\mathrm{pH}$, inducing a more extended structure. The saturation amount of pectin adsorbed $\left(\Gamma_{\mathrm{s}}\right)$ on all the surface-treated stainless steel particles increased with decreasing $\mathrm{pH}$, showing the largest values at $\mathrm{pH}$ 2.5. The $\Gamma_{\mathrm{s}}$ also depended on the apparent density of the positive surface charge of stainless steel particles. It was found that the relative binding strength of unionized pectin on positively charged stainless steel surfaces was lower than that of ionized molecules and it also depended on the apparent density of the positive surface charge of stainless steel particles. These results showed that the surface charge of stainless steel, as well as the degree of the ionization of pectin, was an important factor determining the adsorption behavior of pectin at stainless steel-water interfaces.
\end{abstract}

Key words: Stainless steel/ Surface charge/ Pectin/ Adsorption behavior/ Binding strength.

\section{INTRODUCTION}

The adsorption behavior of acidic polysaccharides at solid-water interfaces, with reference to fouling and biofilm problems, is a subject of great importance in the food industry. Pectins are naturally occurring acidic polysaccharides and major cell wall components in plants (Olson et al., 1969). Pectins, mainly extracted from citrus peel and apple pomace, are widely used as thickening and gelling agents for various kinds of processed foods and beverages. Approximately 70 to $80 \%$ of pectins is composed of $\alpha-1,4$ linked $D$-galacturonic acid units with varying degrees of methylated carboxyl groups, and the remainder is composed of several neutral sugars (Baig and Burgin, 1982; Rees and Wight, 1971). Monovalent cation salts of pectins are highly ionized in aqueous solution and they have random coil conformation with flexibility (Chou et al., 1991). The gels and aggre-

*Corresponding author. Tel : +81-86-286-9600, Fax : +8186-286-9632. gates of pectins are formed and stabilized through cross-linkage between carboxyl groups by divalent cations, hydrogen bonds, and hydrophobic interaction (Oakenfull and Scott, 1984; Rees, 1969). Thus, pectins have a strong tendency to adsorb onto various equipment surfaces because of a diversity of functional groups and their amphipathic nature. On the other hand, the accumulation of large quantities of extracellular polymeric substances, called glycocalyx, is a characteristic of the formation of biofilms or adsorbed microbial communities (Costerton and Irvin, 1981; Harris and Mitchell, 1973; Mattila-Sandholm and Wirtanen, 1992). A glycocalyx matrix usually contains an acidic polysaccharide such as uronic acid, and it plays mediating roles both in the firmer adhesion of microbes to the surface and in the protection of microbes from hostile environments (Carpentier and Cerf, 1993).

In avoiding and minimizing fouling and biofilm formation, the smoothness and physicochemical properties of equipment surfaces are very important factors (European Hygienic Equipment Design Group, 1993a 
and 1993b; McGuire and Krisdhasima, 1991). Stainless steel has been the most widely used material in the construction of food machinery because of its excellent corrosion resistance. The food-contact surfaces of stainless steel can be treated by mechanical polishing and electropolishing to obtain smooth surfaces on which it is easier to remove microbes and repress biofilm formation (Mattila-Sandholm and Wirtanen, 1992; Timperley, 1981). However, the properties of passive film on stainless steel depend strongly on conditions of passivation and pretreatment (Rossi and Elsener, 1995; Virtanen and Bohni, 1995), even if the smoothness of surfaces is of the same order of magnitude. Apparently, the electrostatic nature of stainless steel would also vary by surface treatment, which in turn may affect the adsorption affinity of acidic polysaccharides such as pectin for stainless steel surfaces. However, little is known about the effect of the surface charge of stainless steel on pectin adsorption.

The purpose of this study is to determine the effect of the surface charge of stainless steel on the adsorption behavior of low methoxyl pectin at stainless steelwater interfaces. The authors used surface-treated $316 \mathrm{~L}$ stainless steel particles that have different surface charge properties. This paper describes how the adsorption affinity of pectin for stainless steel depends both on the degree of ionization of pectin and on the apparent density of the positive surface charge of stainless steel particles.

\section{MATERIALS AND METHODS}

\section{Chemicals and materials}

A citrus pectin with a degree of esterification of approximately $35 \%$ was purchased from Wako Pure Chemical Industries, Ltd. (Osaka) and it was used as received. All other chemicals were of analytical grade and were purchased from commercial sources. Nonporous stainless steel particles (SUS 316L) with the specific surface area of $0.34 \mathrm{~m}^{2} / \mathrm{g}$ were obtained from The Nilaco Corp. (Tokyo). Before use, stainless steel particles were washed with acetone and ethanol with sonication, and then dried at $150^{\circ} \mathrm{C}$ (non-surfacetreated stainless steel particles).

\section{Surface treatment of stainless steel particles}

Each 20-g aliquot of stainless steel particles was (i) chemically passivated with $200 \mathrm{ml}$ of $30 \% \mathrm{HNO}_{3}$ for $1 \mathrm{~h}$ at $60^{\circ} \mathrm{C}$, (ii) heated in a furnace at $300^{\circ} \mathrm{C}$ for 4 $\mathrm{h}$, or (iii) exposed to $0.2 \%(\mathrm{v} / \mathrm{v})$ gaseous ozone generated by a pure oxygen-fed silent discharge ozonizer (Model 961; OHNIT Co. Ltd., Okayama) for 1 h. A 10$\mathrm{g}$ aliquot of the $\mathrm{HNO}_{3}$-passivated particles obtained was (iv) further exposed $0.2 \%$ gaseous ozone as described above. After these treatments, the surfacetreated stainless steel particles were rinsed with 200 $\mathrm{ml}$ of deionized water in 500-ml centrifugation tube 10 times by centrifugation ( $1700 \times g$ for $5 \mathrm{~min}$ ), and then dried at $150^{\circ} \mathrm{C}$. Specific surface areas of the particles treated with $30 \% \mathrm{HNO}_{3}, 30 \% \mathrm{HNO}_{3}+0.2 \%$ ozone, $0.2 \%$ ozone, and heating at $300^{\circ} \mathrm{C}$, as determined by the BET method, were $0.41,0.42,0.42$, and $0.39 \mathrm{~m}^{2} / \mathrm{g}$, respectively.

\section{Adsorption experiment}

The experimental procedure was the same as that used for protein adsorption (Urano and Fukuzaki, 2000) without minor modifications. Pectin solution was freshly prepared before each adsorption experiment by dissolving 0.2 to $1.0 \mathrm{~g}$ of pectin in $100 \mathrm{ml}$ of $10^{-3} \mathrm{M} \mathrm{KNO}_{3}$ solution. The $\mathrm{pH}$ value of pectin solution was adjusted to 2.5 to 5.0 with $\mathrm{HNO}_{3}$ or $\mathrm{KOH}(0.1 \mathrm{M}$ solution). A 3-ml aliquot of the pectin solution was introduced to a $25-\mathrm{ml}$ glass vial containing $2.0 \mathrm{~g}$ of stainless steel particles. Then, the vial was reciprocally shaken at $40^{\circ} \mathrm{C}$ (140 oscillations per min) for 2 $\mathrm{h}$. The pectin-adsorbed particles were washed twice with $5 \mathrm{ml}$ of $10^{-3} \mathrm{M} \mathrm{KNO}_{3}$ solution by centrifugation $(2300 \times g$ for $10 \mathrm{~min})$. After being washed, the particles were dried at $40^{\circ} \mathrm{C}$ for $16 \mathrm{~h}$. The dried pectinadsorbed particles were used for the determination of the amount of pectin adsorbed $(\ulcorner)$ and the cleaning experiment. Each adsorption experiment was replicated three times at each $\mathrm{pH}$.

\section{Cleaning experiment}

A 1-g portion of pectin-adsorbed stainless steel particles was put in a stainless steel column $(4 \mathrm{~mm} \phi \times$ $50 \mathrm{~mm}$ ), which was then installed vertically in a column oven at $40^{\circ} \mathrm{C}$. First, $10^{-3} \mathrm{M} \mathrm{KNO}_{3}$ solution $(\mathrm{pH}$ 5.9) was allowed to flow upward through the column at a flow rate of $0.3 \mathrm{ml} / \mathrm{min}$, which corresponds to a space time $(\tau)$ of $1.6 \mathrm{~min}$, for $120 \mathrm{~min}$ both to fill the column with the solution and to wet the particles. Second, $\mathrm{NaOH}$ solution ( $\mathrm{pH} 12.1$ to 13.1) was then fed from the bottom of the column at $\tau$ of $1.6 \mathrm{~min}$. When the $\mathrm{NaOH}$ solution reached the column outlet after 7 min of feeding, the alkali eluent was fractionally collected at intervals of $2 \mathrm{~min}$, and then at intervals of 5,7 , and $10 \mathrm{~min}$, depending on the amount of desorbed pectin. The natural logarithm of the relative amount of residual pectin at time $t(S)$ to that immediately before feeding $\mathrm{NaOH}\left(S_{0}=\Gamma\right)$, In $\left(S / S_{0}\right)$, was plotted against $t$ to obtain the curve of pectin desorption (Urano and Fukuzaki, 2001). 


\section{Surface charge measurements}

Surface charges of stainless steel particles and pectin were determined by potentiometric titration as described previously (Fukuzaki et al., 2001a). A 1.5-g aliquot of stainless steel particles suspended or 0.05 $\mathrm{g}$ of pectin dissolved in $100 \mathrm{ml}$ of $10^{-3} \mathrm{M} \mathrm{KNO}_{3}$ solution $(\mathrm{pH} 2.5)$ was titrated with $0.1 \mathrm{M} \mathrm{KOH}$ under $\mathrm{N}_{2}$ $(99.999 \%, v / v)$ ambient. The uptake of $\mathrm{H}^{+}$and $\mathrm{OH}^{-}$ by stainless steel suspension or pectin solution was measured and compared with the uptake of these ions by a reference solution $\left(10^{-3} \mathrm{M} \mathrm{KNO}_{3}\right.$ solution) of the same liquid volume as that of the suspension or the solution. Since stainless steel particles and pectin used in this study were not made isoionic, the apparent surface charge of stainless steel particles and the apparent net proton charge of pectin were expressed as the relative adsorption density of $\mathrm{H}^{+}$and $\mathrm{OH}^{-}$ $\left(\left[\left\ulcorner\mathrm{H}^{+}-\Gamma \mathrm{OH}^{-}\right]\right)\right.$as a function of the dispersion $\mathrm{pH}$, where $\Gamma_{\mathrm{H}^{+}}$and $\Gamma_{\mathrm{OH}^{-}}$are the adsorption densities of $\mathrm{H}^{+}$and $\mathrm{OH}^{-}$, respectively.

\section{Analyses}

Pectin was determined by using a total organic carbon analyzer (TOC-5000A; Shimadzu Co., Kyoto) equipped with a solid sample module (SSM-5000A; Shimadzu Co., Kyoto). Most of the inorganic carbon, i.e. carbonate species, in pectin solution was removed by the addition of $\mathrm{HNO}_{3}$ (adjusted to $\mathrm{pH}<1$ ) and bubbling of $\mathrm{N}_{2}$ gas before measurement. A 250- $\mu l$ aliquot of the solution and a 1.0-g aliquot of the pectinadsorbed stainless steel particles were analyzed, respectively. The dry weight of pectin was calculated from the whole carbon content of $37 \%(\mathrm{w} / \mathrm{w})$, as determined by the TOC analyzer with glucose as the standard. The specific surface area of stainless steel particles was determined from the amount of $\mathrm{N}_{2}$ adsorbed (Monosorb; Yuasa lonics Co., Osaka) using the BET equation, assuming the cross-sectional area of $16.2 \AA$ for an $N_{2}$ molecule. The chemical composition of stainless steel surfaces was analyzed by X-ray photoelectron spectroscopy (XPS) as described previously (Fukuzaki et al., 2001b). Measurement of the isotherm of water vapor adsorption onto stainless steel particles $\left(25^{\circ} \mathrm{C}\right)$ and BET analysis of the isotherm were conducted as described previously (Fukuzaki et al., 2001a). Intrinsic viscosities ([ $\eta]$ ) of pectin in $10^{-3} \mathrm{M} \mathrm{KNO}_{3}$ solution were determined at $40^{\circ} \mathrm{C}$ in the $\mathrm{pH}$ range of 2.5 to 6.0 with an Ostwald viscometer by measuring specific viscosities $\left(\eta_{\mathrm{sp}}\right)$ at pectin concentrations $(c)$ of $5 \times 10^{-3}$ to $5 \times 10^{-2} \mathrm{~g} / l$ and by extrapolating the graph of $\eta_{\mathrm{sp}} / c$ versus $c$ to zero concentration.

\section{RESULTS AND DISCUSSION}

\section{Surface properties of surface-treated stainless steel particles}

Table 1 shows the chemical composition of the outermost surfaces of the surface-treated stainless steel particles and the results of BET analysis of water adsorption isotherms on the particles. $\mathrm{HNO}_{3}$ treatment resulted in the enrichment of chromium content, whereas heat treatment led to the enrichment of iron content. Ozone treatment of non-surface-treated and $\mathrm{HNO}_{3}$-treated particles resulted in no significant changes in the chemical composition of their outermost surfaces. The monolayer saturation amount $\left(V_{m}\right)$ is the amount of water physisorbed onto surface hydroxyl groups $(\mathrm{M}-\mathrm{OH})$ on stainless steel particles through hydrogen bonding, and hence it reflects the number of surface hydroxyl groups. The BET $c$ constant also reflects the adsorption affinity of water for stainless steel surfaces. Lower $V_{\mathrm{m}}$ and BET $c$ values were obtained for all the surface-treated particles

TABLE 1. Atomic composition of the outermost surfaces of and BET analysis of water adsorption data onto the surface-treated stainless steel particles.

\begin{tabular}{|c|c|c|c|c|c|c|}
\hline \multirow[b]{2}{*}{ Stainless steel } & \multicolumn{4}{|c|}{ Component (atom \%) } & \multicolumn{2}{|c|}{$\mathrm{H}_{2} \mathrm{O}$ adsorption } \\
\hline & $\mathrm{Cr}$ & $\mathrm{Fe}$ & $\mathrm{O}$ & C & $\begin{array}{c}V_{\mathrm{m}} \\
\left(\mathrm{ml} / \mathrm{m}^{2}\right)\end{array}$ & $\begin{array}{l}C \\
(-)\end{array}$ \\
\hline Non-surface-treated ${ }^{a}$ & 3.6 & 4.2 & 54.7 & 23.5 & 0.32 & 26.3 \\
\hline $30 \% \mathrm{HNO}_{3}$-treated & 8.9 & 1.9 & 54.2 & 21.9 & 0.21 & 17.2 \\
\hline $30 \% \mathrm{HNO}_{3}+0.2 \%$ ozone-treated & 7.4 & 1.7 & 52.1 & 29.1 & 0.20 & 13.9 \\
\hline $0.2 \%$ ozone-treated $^{a}$ & 3.3 & 3.5 & 51.9 & 22.7 & 0.28 & 24.8 \\
\hline Heat-treated $\left(300^{\circ} \mathrm{C}\right)$ & 2.5 & 6.2 & 53.1 & 28.4 & 0.23 & 21.0 \\
\hline
\end{tabular}

For XPS analysis, argon ion etching was not conducted. Another major main spectrum was observed at $101.7 \mathrm{eV}$ which was assigned to Si $2 \mathrm{p}$. A linearized form of the BET equation was fitted to the water vapor adsorption data in the relative vapor pressure range of 0.05 to 0.30 based on a linear regression method.

${ }^{a}$ Reported by Fukuzaki et al. (2001b). 


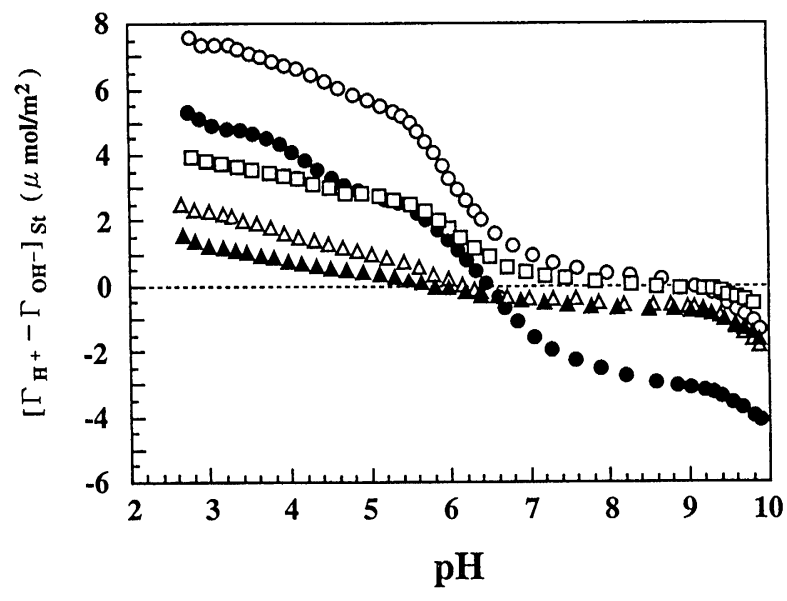

FIG. 1. [ $\left[\mathrm{H}^{+}-\Gamma \mathrm{OH}^{-}\right]$st curves of non-surface-treated and surface-treated stainless steel particles as a function of $\mathrm{pH}$. Titration curves were measured in the presence of $10^{-3} \mathrm{M}$ $\mathrm{KNO}_{3}$. Symbols: $\mathrm{O}$, Non-surface-treated; $0.2 \%$ ozonetreated; $\square$, heat-treated at $300^{\circ} \mathrm{C} ; \triangle, 30 \% \mathrm{HNO}_{3}$-treated; $\boldsymbol{\Delta}, 30 \% \mathrm{HNO}_{3}+0.2 \%$ ozone-treated particles.

compared with those for non-surface-treated particles. These results indicated that passive films having smaller numbers of surface hydroxyl groups were formed on stainless steel particles, with varying degrees of dehydroxylation, by treatments with $\mathrm{HNO}_{3}$, gaseous ozone, and heating.

Figure 1 compares the curves of the relative adsorption density of $\mathrm{H}^{+}$and $\mathrm{OH}^{-}$on non-surfacetreated and surface-treated stainless steel particles $\left(\left[\Gamma_{\mathrm{H}^{+}}-\Gamma_{\mathrm{OH}^{-}}\right]_{\mathrm{st}}\right)$ as a function of $\mathrm{pH}$. Stainless steel particles having different surface charge properties could be successfully prepared by the surface treatments examined. Non-surface-treated and all the surface-treated particles were positively charged $\left(\left[\left\ulcorner\mathrm{H}^{+}-\Gamma \mathrm{OH}^{-}\right] \mathrm{st}>0\right)\right.$ over the $\mathrm{pH}$ range of 2.5 to 5.0 although the absolute values of $\left[\Gamma_{\mathrm{H}^{+}}-\Gamma_{\mathrm{OH}}\right]_{\mathrm{st}}$ were very different. The surface charge of stainless steel is believed to be established by protonation $\left(\mathrm{M}-\mathrm{OH}_{2}^{+}\right)$ or deprotonation $\left(\mathrm{M}-\mathrm{O}^{-}\right)$of surface hydroxyl groups, and therefore a variation in the $\left[\mathrm{r}_{\mathrm{H}^{+}}-\Gamma_{\mathrm{OH}^{-}}\right]_{\mathrm{St}}$ curves appears to be correlated with the degree of surface dehydroxylation (see Table 1). Since protonated hydroxyl groups $\left(\mathrm{M}-\mathrm{OH}_{2}^{+}\right)$on stainless steel surfaces are considered to act as adsorption sites for negatively charged pectin, the surfaces having a high $\left[\Gamma_{\mathrm{H}^{+}}-\Gamma_{\mathrm{OH}}^{-}\right]_{\mathrm{st}}$ value would exhibit a higher affinity for pectin adsorption.

\section{Charge property and molecular size of pectin}

Figure 2 shows the curve of the relative adsorption density of $\mathrm{H}^{+}$and $\mathrm{OH}^{-}$on pectin $\left(\left[\mathrm{\Gamma}_{\mathrm{H}^{+}}-\Gamma_{\mathrm{OH}^{-}}\right]{ }_{\mathrm{Pec}}\right)$ and $[\eta]$ of pectin as a function of $\mathrm{pH}$. The absolute value of $\left[\Gamma_{\mathrm{H}^{+}}-\Gamma_{\mathrm{OH}}^{-}\right]$Pec curve increased with incre-

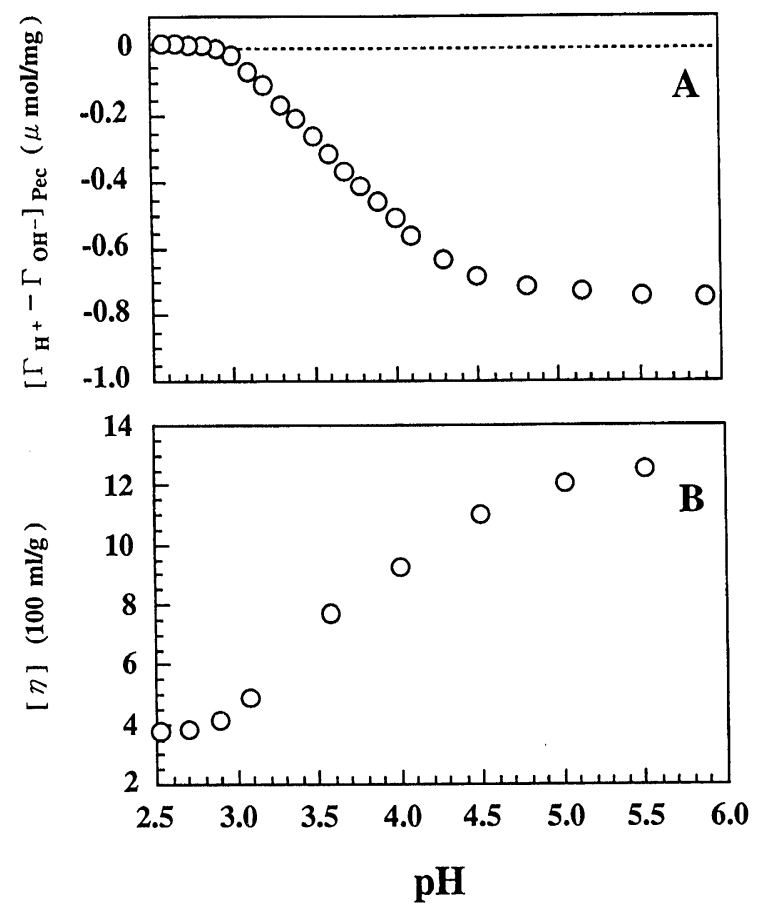

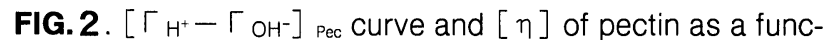
tion of $\mathrm{pH}$. Titration curve and specific viscosity $\left(40^{\circ} \mathrm{C}\right)$ of pectin were measured in the presence of $10^{-3} \mathrm{M} \mathrm{KNO}_{3}$

asing $\mathrm{pH}$ owing to the ionization of free carboxyl groups on the molecule (Fig. $2 \mathrm{~A}$ ). $\left[\mathrm{\Gamma}_{\mathrm{H}}-\Gamma_{\mathrm{OH}^{-}}\right]$Pec was almost zero below $\mathrm{pH} 2.7$, indicating that pectin was in unionized form. The $[\eta]$ value, a measure of the hydrodynamic volume occupied by the molecule, became the lowest at $\mathrm{pH} 2.5$ to 2.7 and increased with increasing $\mathrm{pH}$ (Fig. 2B). Apparently, the [ $\eta]$ value was correlated with $\left[\Gamma_{\mathrm{H}^{+}}-\Gamma_{\mathrm{OH}^{-}}\right]$Pec. Fishman et al. (1984) reported that the size of pectins in aqueous solution depended on the degree of esterification of carboxyl groups and ionic strength, and hence on the strength of the coulombic repulsion. These results indicate that unionized pectin was a more compact random coil, whereas the distribution of negative charges along the pectin molecule induced an extended form through coulombic repulsion.

\section{Adsorption of pectin}

Figure 3 shows the isotherms of pectin adsorption on non-surface-treated stainless steel particles at $\mathrm{pH}$ 2.5 and 3.5. The isotherms exhibited well-defined saturation values $\left(\Gamma_{s}\right)$. The $\Gamma_{s}$ values were almost constant when adsorption time was prolonged from 2 to $14 \mathrm{~h}$ (data not shown). A significantly higher $\Gamma \mathrm{s}$ was observed at $\mathrm{pH} 2.5$ compared with that at $\mathrm{pH} 3.5$. To determine the effect of $\mathrm{pH}$ on $\Gamma_{\mathrm{s}}$, the $\Gamma_{\mathrm{s}}$ values on all the stainless steel particles were determined over the $\mathrm{pH}$ range of 2.5 to 5.0 . Figure 4 shows the $\Gamma \mathrm{s}$ 


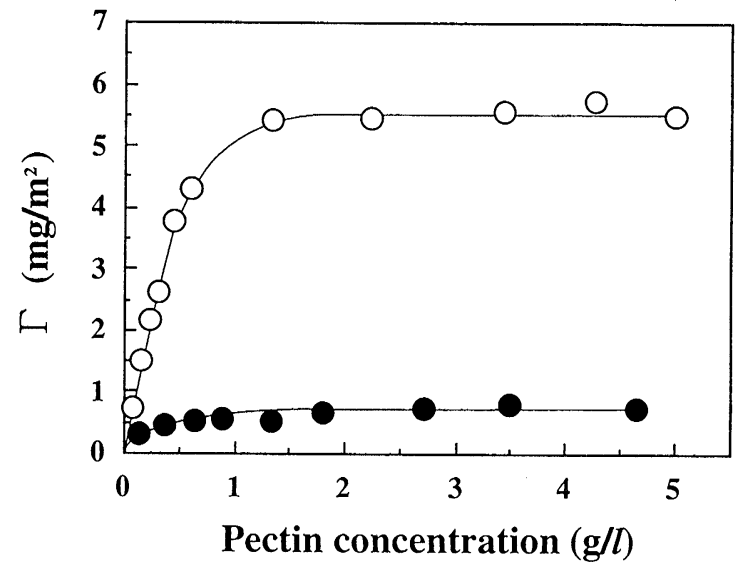

FIG. 3. Adsorption isotherms of pectin on non-surfacetreated stainless steel particles at $\mathrm{pH} 2.5$ and 3.5. The adsorption experiment was conducted at $40^{\circ} \mathrm{C}$ in the presence of $10^{-3} \mathrm{M} \mathrm{KNO}_{3}$ for $2 \mathrm{~h}$ with reciprocal shaking (140 oscillations per min). Symbols: $\bigcirc, \mathrm{pH} 2.5$;, $\mathrm{pH} 3.5$.

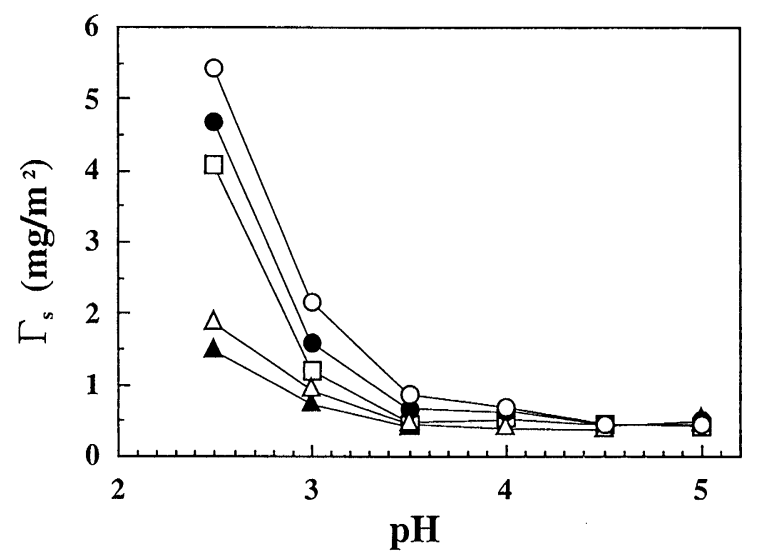

FIG. 4. $\Gamma_{s}$ values on non-surface-treated and surfacetreated stainless steel particles as a function of $\mathrm{pH}$. For experimental conditions, see the legend for Fig. 3. Symbols: $\bigcirc$. Non-surface-treated; $0.2 \%$ ozone-treated; $\square$, heattreated at $300^{\circ} \mathrm{C} ; \triangle, 30 \% \mathrm{HNO}_{3}$-treated; $\mathbf{\Delta}, 30 \% \mathrm{HNO}_{3}+$ $0.2 \%$ ozone-treated particles.

values on non-surface-treated and surface-treated stainless steel particles as a function of $\mathrm{pH}$. On all the stainless steel particles, $\Gamma \mathrm{s}$ tended to increase with decreasing $\mathrm{pH}$ and showed the largest values at $\mathrm{pH}$ 2.5. On the other hand, $\Gamma_{\mathrm{s}}$ also depended on the kind of stainless steel particles. Higher $\Gamma_{s}$ values were observed on the stainless steel particles having larger numbers of surface hydroxyl groups and higher $\left[\mathrm{CH}_{\mathrm{H}^{+}}\right.$

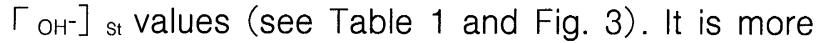
likely that $\Gamma_{\mathrm{s}}$ depends on the surface charge (or the degree of hydroxylation) of stainless steel particles rather than the surface chemical composition. The effect of the surface charge of stainless steel particles on $\Gamma_{\mathrm{s}}$ disappeared at $\mathrm{pH}$ above 4.0. The dependence of $\Gamma_{\mathrm{s}}$ on solution $\mathrm{pH}$ is evidently attributed to the substantial differences in the degree of ionization and molecular size of pectin depending on $\mathrm{pH}$ (see Fig. 2). The phenomena that the net charge and size of polyelectrolytes affect their $\Gamma_{s}$ on stainless steel and oxide surfaces is commonly found for protein adsorption (Fukuzaki et al., 1995 and 1996; Koutsoukos et al., 1983; Norde et al., 1986). The unionized pectin forms a more compact structure and shows little lateral electrostatic repulsion. These can lead to intermolecular hydrogen bonds between hydroxyl groups and/or hydrophobic interaction between the ester methyl groups (Fishman et al., 1984; Oakenfull and Scott, 1984), and hence to a closely packed arrangement on stainless steel surfaces. In contrast, an extended form of highly ionized pectin shows intermolecular electrostatic repulsion and requires a larger contact surface area per molecule for adsorption, resulting in smaller $\Gamma_{\mathrm{s}}$ values. Judging from both the well-defined saturation values of isotherms and the effect of the surface charge of stainless steel on $\Gamma_{\mathrm{s}}$, it is thought that unionized and ionized pectins are probably adsorbed in a monolayer on stainless steel surfaces, where electrostatic interactions and hydrogen bonds contribute to the attractive force.

\section{Interactions between pectin and stainless steel surfaces}

A cleaning experiment was conducted to assess the effect of adsorption $\mathrm{pH}$ on the relative binding strength of pectin. Figure 5 shows the desorption curves of pectins that had been adsorbed on non-

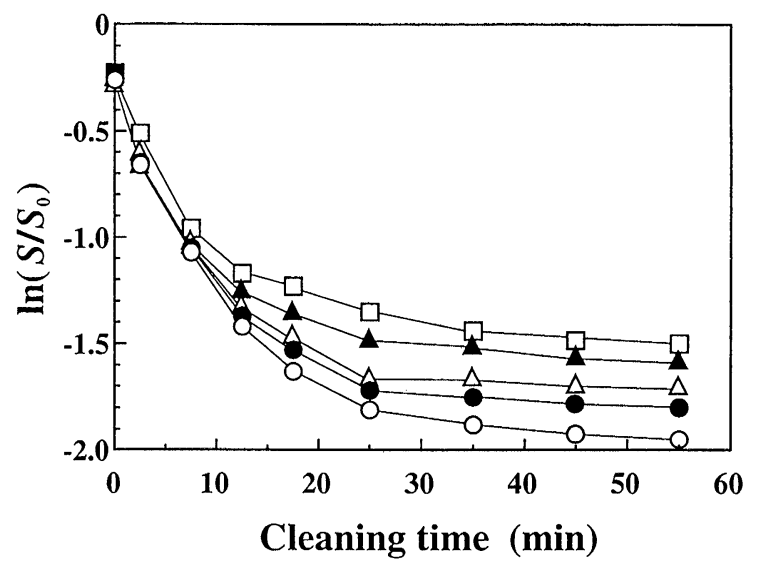

FIG.5. Effect of adsorption $\mathrm{pH}$ on the desorption behavior of pectin from non-surface-treated stainless steel particles during cleaning with $\mathrm{NaOH}$ solution of $\mathrm{pH}$ 13.1. Each cleaning experiment was conducted in a stainless steel column at $40^{\circ} \mathrm{C}$ by continuously feeding the $\mathrm{NaOH}$ solution at $\tau$ of 1.6 min. Symbols (adsorption $\mathrm{pH}$ ): $\bigcirc, 2.50 ; 0,2.75 ; \triangle, 3.00$; $\boldsymbol{\Delta}, 3.25 ; \square, 3.50$. 
surface-treated stainless steel particles at $\mathrm{pH} 2.5$ to $3.5\left(\Gamma=\right.$ ca. $\left.0.7 \mathrm{mg} / \mathrm{m}^{2}\right)$ during cleaning with $\mathrm{NaOH}$ solution of $\mathrm{pH}$ 13.1. Before feeding the $\mathrm{NaOH}$ solution, approximately 20 to $23 \%$ of the fragments of the pectin molecules, corresponding to $\ln \left(S / S_{0}\right)$ at time zero, were eluted from the dried pectin-adsorbed particles with $\mathrm{KNO}_{3}$ solution. The initial rate of pectin desorption increased slightly by decreasing the adsorption $\mathrm{pH}$. In addition, the equilibrium amount of residual pectin $\left(S_{\mathrm{r}}\right)$ after 55 min of cleaning decreased from 0.16 to $0.10 \mathrm{mg} / \mathrm{m}^{2}$ with decreases in the adsorption $\mathrm{pH}$ from 3.5 to 2.5. The difference in the desorption behavior depending on the adsorption $\mathrm{pH}$ was probably attributed to the degree of the ionization of pectin. The ionized pectin interacts with the stainless steel surface through the formation of ion pairs at the contact region. Certainly, an increase in the degree of the ionization of pectin can enhance the opportunity of these bonding events, resulting in the greater magnitude of the forces of electrostatic interaction. On the other hand, the attractive forces between unionized pectin and stainless steel surfaces would be predominantly hydrogen bonds between polar groups $(-\mathrm{COOH},-\mathrm{OH})$ on the pectin molecule and surface hydroxyl groups on stainless steel particles. In this adsorption state, pectin is weakly adsorbed and it can be readily desorbed during alkali treatment.

Pectin was adsorbed on non-surface-treated and surface-treated stainless steel particles $(\Gamma=$ ca. 1.3 $\mathrm{mg} / \mathrm{m}^{2}$ ) at $\mathrm{pH} 2.5$, where pectin was unionized, and

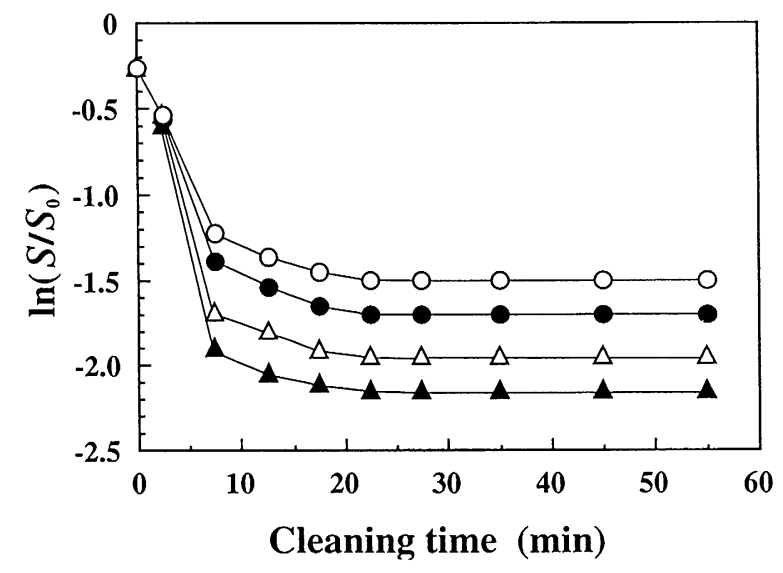

FIG.6. Effect of surface treatments of stainless steel particles on the desorption behavior of pectin during cleaning with $\mathrm{NaOH}$ solution of $\mathrm{pH}$ 12.1. Pectin was adsorbed on the surface-treated stainless steel particles at $\mathrm{pH} 2.5$. For cleaning conditions, see the legend for Fig. 5. Symbols: $\bigcirc$, Nonsurface-treated; $0.2 \%$ ozone-treated $(0.2 \%) ; \triangle, 30 \%$ $\mathrm{HNO}_{3}$-treated; $\boldsymbol{\Delta}, 30 \% \mathrm{HNO}_{3}+0.2 \%$ ozone-treated particles. then each of the pectin-adsorbed particles was cleaned with $\mathrm{NaOH}$ solution of $\mathrm{pH} 12.1$ (Fig. 6). The desorption behavior of unionized pectin was also found to be affected by the surface charge of stainless steel particles. Significant differences were observed in the $S_{r}$ value. The $S_{r}$ values on non-surfacetreated, heat-treated, $\mathrm{HNO}_{3}$-treated, and $\mathrm{HNO}_{3}+\mathrm{O}_{3}$ treated particles were $0.29,0.24,0.19$, and $0.15 \mathrm{mg} /$ $\mathrm{m}^{2}$, respectively. This result suggests that the relative binding strength of unionized pectin depends on positive $\left[\mathrm{H}_{\mathrm{H}}-\Gamma_{\mathrm{OH}}\right]_{\mathrm{st}}$ value, i.e., the number of basic hydroxyl groups on stainless steel surfaces for hydrogen bonding. It is conceivable that the magnitude of forces of hydrogen bonds between unionized pectin molecules and hydroxyl groups on stainless steel surfaces depends on the strength of the basicity of hydroxyl groups on stainless steel and that it might become greater on protonated hydroxyl groups (M$\mathrm{OH}_{2}^{+}$) on stainless steel because of the contribution of electrostatic forces.

The results showed that the electrostatic nature of stainless steel surfaces, as well as the degree of the ionization of pectin, was an important factor determining the adsorption behavior of pectin at stainless steel-water interfaces. The adsorption affinity of pectin for stainless steel could be reduced by modifying stainless steel surfaces to an electrostatically inert nature. Among the surface treatments studied, $\mathrm{HNO}_{3}$ treatment was the most effective to reduce the number of hydroxyl groups and hence the surface charge density of stainless steel, rendering the surface less susceptible to pectin adsorption. These findings suggest that controlling the surface charge of stainless steel is of importance in improving resistance to the adsorption of other ionic compounds, including bacterial extracellular polymers.

\section{REFERENCES}

Baig, M. M., Burgin, C. W., and Cerda, J. J. (1982) Fractionation and study of the chemistry of pectic polysaccharides. J. Agric. Food Chem., 30, 768-770.

Carpentier, B., and Cerf, O. (1993) Biofilms and their consequences, with particular reference to hygiene in the food industry: a review of the literature. J. Appl. Bacteriol., 75, 499-511.

Chou, T. C., Pintauro, N., and Kokini, J. L. (1991) Conformation of citrus pectin using small amplitude oscillatory rheometry. J. Food Sci., 56, 1365-1371.

Costerton, J. W., Irvin, R. T., and Chen, K.-J. (1981) The bacterial glycocalyx in nature and disease. Annu. Rev. Microbiol., 35, 299-324.

European Hygienic Equipment Design Group (1993a) Hygienic equipment design criteria. Trends Food Sci. 
Technol., 4, 225-229.

European Hygienic Equipment Design Group (1993b) Welding stainless steel to meet hygienic requirements. Trends Food Sci. Technol., 4, 306-310.

Fishman, M. L., Pfeffer, P. E., Barford, R. A., and Doner, L. W. (1984) Studies of pectin solution properties by highperformance size exclusion chromatography. J. Agric. Food Chem., 32, 372-378.

Fukuzaki, S., Urano, H., and Nagata, K. (1995) Adsorption of protein onto stainless-steel surfaces. J. Ferment. Bioeng., 80, 6-11.

Fukuzaki, S., Urano, H., and Nagata, K. (1996) Adsorption of bovine serum albumin onto metal oxide surfaces. J. Ferment. Bioeng., 81, 163-167.

Fukuzaki, S., Urano, H., Hiramatsu, M., and Takehara, A. (2001a) Effect of ozone on the surface charge and cleanability of stainless steel. Biocontrol Sci., 6, 87-94.

Fukuzaki, S., Urano, H., Hiramatsu, M., and Takehara, A. (2001b) Surface treatment and facilitated cleaning of stainless steel by ozonized air. Biocontrol Sci., 6, 95-101.

Harris, R., and Mitchell, R. (1973) The role of polymers in microbial aggregation. Annu. Rev. Microbiol., 27, 27-50.

Koutsoukos, P. G., Norde, W., and Lyklema, J. (1983) Protein adsorption on hematite $\left(\alpha-\mathrm{Fe}_{2} \mathrm{O}_{3}\right)$ surfaces. $J$. Colloid Interface Sci., 95, 385-397.

McGuire, J., and Krisdhasima, V. (1991) Surface chemical influences on protein adsorption kinetics. Food Technol., 45, 82-96.

Mattila-Sandholm, T., and Wirtanen, G. (1992) Biofilm formation in the industry: a review. Food Rev. Int., 8, 573603.

Norde, W., MacRitchie, F., Nowicka, G., and Lyklema, J. (1986). Protein adsorption at solid-liquid interfaces: reversibility and conformation aspects. J. Colloid Interface
Sci., 112, 447-456.

Oakenfull, D., and Scott, A. (1984) Hydrophobic interaction in the gelation of high methoxyl Pectins. J. Food Sci., 49, 1093-1098.

Olson, A. C., Evans, J. J., Frederic, D. P., and Jensen, E. F. (1969) Plant suspension culture media macromoleculespectic substances, protein, and peroxidase. Plant. Physiol., 44, 1594-1600.

Paoletti, S., Cesaro, A., Delben, F., and Ciana, A. (1986) Ionic effects on the conformation, equilibrium, properties and rheology of pectate in aqueous solutions and gels. In Chemistry and Function of Pectins, ACS Symposium Series 310, Washington DC.

Rees, D. A. (1969) Structure, conformation and mechanism in the formation of polysaccharide gels and networks. Adv. Carbohydr. Chem. Biochem., 24, 267-332.

Rees, D. A., and Wight, A. W. (1971) Polysaccharide conformation. Part VII. Model building computations for $\alpha-1$, 4 linked D-galacturonan and the kinking function of L-rhamnose residues in pectic substances. J. Chem. Soc., (B), 1366-1372.

Rossi, A., and Elsener, B. (1995) Ageing of passive films on stainless steels in sulfate solutions - XPS analysis. Mater. Sci. Forum, 185-188, 337-346.

Urano, H., and Fukuzaki, S. (2000) Conformation of adsorbed bovine serum albumin governing its desorption behavior at alumina-water interfaces. J. Biosci. Bioeng., 90, 105-111.

Urano, H., and Fukuzaki, S. (2001) Facilitation of cleaning of alumina surfaces fouled with heat-treated bovine serum albumin by ozone treatment. J. Food Prot., 64, 108-112.

Virtanen, S., and Bohni, H. (1995) On the stability of passive films on stainless steels. Mater. Sci. Forum,185-188, 965-974. 